\title{
Resilience and functional capacity of elderly people with diabetes mellitus
}

\author{
Resiliência e capacidade funcional de pessoas idosas com diabetes mellitus
}

Maria Cristina Lins Oliveira Frazão ${ }^{1}$, Cláudia Jeane Lopes Pimenta ${ }^{1}$, Cleane Rosa Ribeiro da Silva ${ }^{1}$, Mateus Carneiro Vicente ${ }^{1}$, Tatiana Ferreira da Costa ${ }^{1}$, Kátia Neyla de Freitas Macedo Costa ${ }^{1}$

Objective: to correlate the resilience and functional capacity of the elderly people with diabetes mellitus. Methods: this is an exploratory, descriptive and cross-sectional study, conducted with 96 elderly patients hospitalized for complications of diabetes mellitus in a university hospital. Data collection was performed through an interview, using a semi-structured instrument called the Resilience Scale and the Barthel Index. Results: most of the elderly people had moderate resilience (57.3\%) and functional dependence (85.4\%), with a mild (30.2\%) and moderate (26.0\%) prevalence. A positive correlation was observed with statistical significance between resilience and functional capacity, so the increase of one variable is correlated with the elevation of the other. Conclusion: when correlating resilience with the functional capacity of the elderly person, a positive and proportional relationship was observed between these variables highlighting the functional capacity as an important instrument for the development of resilience in the elderly person with diabetes.

Descriptors: Resilience, Psychological; Activities of Daily Living; Aged; Diabetes Mellitus.

Objetivo: correlacionar a resiliência e a capacidade funcional de pessoas idosas com diabetes mellitus. Métodos: estudo exploratório, descritivo e transversal, realizado com 96 idosos hospitalizados por complicação do diabetes mellitus em um hospital universitário. A coleta de dados foi realizada por meio de entrevista, utilizando um instrumento semiestruturado, a Escala de Resiliência e o Índice de Barthel. Resultados: a maioria dos idosos apresentou resiliência moderada $(57,3 \%)$ e dependência funcional $(85,4 \%)$, com prevalência leve $(30,2 \%)$ e moderada (26,0\%). Foi observada uma correlação positiva com significância estatística entre a resiliência e a capacidade funcional, de modo que o aumento de uma variável está correlacionado à elevação da outra. Conclusão: ao correlacionar a resiliência com a capacidade funcional dos idosos, observou-se relação positiva e proporcional entre essas variáveis, o que ressalta a capacidade funcional como um importante instrumento para o desenvolvimento da resiliência no idoso com diabetes.

Descritores: Resiliência Psicológica; Atividades Cotidianas; Idoso; Diabetes Mellitus.

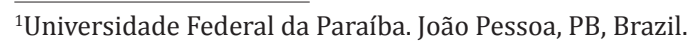

Corresponding author: Cláudia Jeane Lopes Pimenta

Rua Capitão Severino Cesarino da Nóbrega, 431, Jardim São Paulo. CEP: 58051-220. João Pessoa, PB, Brazil. E-mail: claudinhajeane8@ hotmail.com 


\section{Introduction}

In recent years, the concern about the health conditions people are aging has become a topic of relevant discussion, given that the population has become more and more elderly, requiring interventions in the area of health to promote quality of life and well-being ${ }^{(1)}$. Given this context, population aging is associated with an increase in chronic and degenerative diseases and diabetes mellitus stands out, characterized as one of the most frequent pathologies in this people ${ }^{(2)}$.

Diabetes is a metabolic disease associated with serious health damage, which can be irreversible and difficult to treat, damaging the performance of sensory-motor, emotional and mental function ${ }^{(3)}$. Also, it may also negatively affect social roles, work activities, family dynamics and independent living since it is necessary to adapt the elderly to a new daily routine, with changes in lifestyle, adoption of healthy eating habits, regular exercise, regular monitoring of capillary glycemia, self-care activities and medication use $\mathrm{e}^{(3-4)}$.

The vascular and neuropathic complications that affect functional capacity are highlighted among the damages resulting from chronic diseases such as diabetes, directly reflecting the autonomy and independence of the elderly person, which fosters the negative repercussions experienced in the daily life of these individuals, especially in the concerns and anxieties about the control and therapeutics of this morbidity $^{(5)}$.

Functional incapacity is quite common in elderly people with diabetes. This refers to the difficulty or inability to perform daily activities within normal standards, and it is often evaluated through scales that investigate the competence to perform basic activities of daily living and/or instrumental activities of daily life and/or activities related to mobility ${ }^{(6)}$.

Although many elderly people face daily adversities caused by diabetes, it is noticed that some of them have an ability to overcome and maintain an atti- tude towards problems, which may be associated with resilience $^{(4)}$. This has been evidenced as a protection factor in relation to psychological disorders, leading to an increase in self-esteem, self-efficacy, problem-solving skills and greater satisfaction with interpersonal relationships, which represents a personality trait that moderates the negative effects of stress and promotes adaptation $^{(5)}$.

The evaluation of the resilience in the elderly person with diabetes has as a relevant tool since the acceptance of their condition and the limitations imposed by the disease makes the elderly stronger psychosocially and favors the coping of adversities. Resilience can be classified into three dimensions: the first dimension is called resolution of actions and values related to energy, persistence, discipline and the conception of values that give meaning to life, such as friendship, personal fulfillment, and satisfaction of life $^{(7)}$.

The second dimension is of independence and determination characterized by the ability to solve difficult situations, and how to deal with various situations at the same time. The third dimension is self-confidence and ability to adapt to situations, that is, to trust that they can solve problems, as well as take actions against their will and maintain interest in things that they consider important $t^{(7)}$.

The relationship between resilience and the functionality of older people has become the focus of national and international studies ${ }^{(5,8)}$. Knowing how these variables are related can provide support for multidisciplinary team action with the elderly person, both from the point of view of prevention and rehabilitation and for the planning of guidelines for family and caregivers. Thus, it is necessary to use specific and validated scales to ensure the reliability of the data.

Also, the importance of the work of health professionals, among them nurses is highlighted to include the elderly person in social programs of an educational nature, which seek to stimulate the development of the capacity to carry out daily activities 
and favor the understanding and coping with the difficulties experienced ${ }^{(1)}$.

Thus, this study aimed to correlate the resilience and functional capacity of elderly people with diabetes mellitus.

\section{Methods}

This is an exploratory, descriptive and cross-sectional study carried out in the medical and surgical clinics of a university hospital, located in the city of João Pessoa, Paraíba, Brazil.

The study population consisted of elderly people hospitalized for diabetes complications at the hospital in 2015, totaling 126 individuals. The sample size was defined using the calculation for finite populations with a 95\% confidence interval $(\alpha=0.05$, which gives $\left.\mathrm{Z}_{0.05 / 2}=1.96\right)$, an estimated prevalence of $50 \%$ $(\mathrm{p}=0.500)$ and margin of error of $5 \%$ (Error $=0.05)$, which corresponded to 96 participants.

The inclusion criteria established were age equal or greater than 60 years old; have a medical diagnosis of diabetes, and be admitted to the medical or surgical clinic within the last 24 hours before data collection. If the participants had any dementia already diagnosed or with alterations in communication and hearing, they were excluded from the study.

Data collection was performed between November 2016 and February 2017 through an interview using a semi-structured instrument to obtain data related to sociodemographic and clinical profile, containing the variables gender, age, marital status, education level, religion, personal income and family income, type of diabetes, pharmacological therapy, self-reported health status, smoking, alcoholism and difficulty living with the disease. Also, the Resilience Scale and the Barthel Index were used.

The Resilience Scale has 25 items in which the answers vary from 1 (totally disagree) to 7 (totally agree), being composed of three factors: Factor 1 - resolution of actions and values (15 items); Factor 2 - in- dependence and determination (4 items); and Factor 3 - self-confidence and ability to adapt to situations (6 items). Final results range from 25 to 175 points and resilience values are considered high when the score is equal or greater than 147 points. In this study, it was chosen to classify the scale in the following scores: up to 111 - low resilience; from 112 to 146 - moderate resilience; and greater than 147 - high resilience ${ }^{(7)}$.

The Barthel Index assesses functional independence by measuring the individual's ability to perform activities of daily living. This instrument has ten items that evaluate the control of the bladder and bowel sphincters, personal hygiene, independence in the bathroom, feeding, chair transfer, gait, ability to dress and bathe, and to climb stairs, in which, the final score classify the patients as dependent when it is very severe $(0-4)$, severe $(0-5)$, moderate $(10-14)$, mild $(15-19)$ and independent $(20)^{(9)}$.

The collected data was compiled and stored in the Microsoft Office Excel program and then imported into the Statistical Package for Social Sciences application 22.0 to perform the descriptive statistical analyzes.

The Kolmogorov-Smirnov test was used to verify the normality of the numerical data. For the correlation between the variables, the Spearman correlation test was used because it was a nonparametric variable. The level of significance used throughout the study was 0.05 .

The study complied with the norms of resolution 466/12 involving human beings and it was approved by the Research Ethics Committee of the Lauro Wanderley University Hospital under opinion $\mathrm{n}^{-}$ $1,581,777$.

\section{Results}

A total of 96 elderly people participated in the study, with a prevalence of women (55.2\%), aged 6069 years old $(60.4 \%)$, with a mean age of 68.58 years old $( \pm 6.935)$. married or with a partner $(54.2 \%)$, 
with incomplete elementary education (36.5\%), who are practicing the Catholic religion $(72.9 \%)$, retired (71.9\%), who have a personal income and between $\mathrm{R} \$ 880$ and $\mathrm{R} \$ 1,760$ (81.3\% and $85.4 \%$, respectively) and who live in João Pessoa (55.2\%).

Regarding health conditions, most of the elderly participants had type 2 diabetes (96.9\%), used only oral hypoglycemic as a pharmacological therapy (45.8\%), assessed their health as regular (61.5\%), did not smoke $(93.8 \%)$, did not consume alcoholic beverages $(99.0 \%)$ and reported difficulties in living with the disease (40.6\%). Regarding the resilience levels of the elderly participants, a moderate prevalence was found in 55 (57.3\%), low in 33 (34.3\%) and high in $8(8.3 \%)$ participants. The items that presented the greatest impairment were I have enough energy to do what I have to do (3.83), It's okay if there are people who don't like me $(4,11)$ and I can be on my own if I have to $(4,23)$.

As to the functional capacity of the elderly person with diabetes, it was observed that most of them presented dependence (85.4\%), most of them with mild dependence (30.2\%) and moderate $(26.0 \%)$. The "Dressing Up" and "Bathe" domains presented the greatest impairment, in which the most of the elderly people were dependent or needed help to perform such activities, corresponding to $60.4 \%$ and $56.3 \%$, respectively (Table 1).

Table 1 - Distribution of data on the functional capacity of the elderly with diabetes mellitus

\begin{tabular}{lc}
\hline Functional capacity & n (\%) \\
\hline Dependent & $82(85.4)$ \\
Very severe & $17(17.7)$ \\
Severe & $11(11.5)$ \\
Moderate & $25(26.0)$ \\
Mild & $29(30.2)$ \\
Independent & $14(14.6)$ \\
Total & $96(100.0)$ \\
\hline
\end{tabular}

When correlating Resilience scores and their factors with the functional capacity of the elderly participants in the study, a positive correlation was observed with statistical significance $(\mathrm{p} \leq 0.050)$ between the variables, so the increase in the functional capacity of the elderly person is correlated with increased resilience (Table 2).

Table 2 - Correlation between resilience scores and functional capacity of elderly patients with diabetes mellitus

\begin{tabular}{lcc}
\hline \multirow{2}{*}{ Resilience } & \multicolumn{2}{c}{ Functional capacity } \\
\cline { 2 - 3 } & $\mathbf{r}$ & $\mathbf{p}^{*}$ \\
\hline Factor 1 & 0.293 & 0.004 \\
Factor 2 & 0.327 & 0.001 \\
Factor 3 & 0.326 & 0.001 \\
General & 0.331 & 0.001 \\
*Spearman & &
\end{tabular}

\section{Discussion}

This study shows limitations related to the use of the cross-sectional method, which does not result in cause and effect, preventing a more precise understanding of the impact of resilience in the practice of self-care.

Most of the participants had a moderate level of resilience, which could be related to the fact that they are elderly, so because of their past experience, they would have experienced a greater number of risk events and developed coping strategies effective over time ${ }^{(5)}$. Also, the chronic condition and the need to overcome the limitations caused by diabetes on a daily basis may favor the mechanisms that form the resilience ${ }^{(10)}$.

The fact that there is a prevalence of married elderly participants can also contribute to the increase of resilience, since the presence of the spouse, in most cases, provides greater social support and instrumental and emotional support received ${ }^{(11)}$. A study of elderly diabetics in the UK found that family and social support was an important element in the development of resilience, directly influencing the improvement of quality of life and coping with diabetes-related adversities ${ }^{(12)}$.

The evaluation of functional capacity revealed 
a predominance of elderly people with mild or moderate dependence to perform daily life activities, which could be justified by the characteristics of diabetes, such as reduced plantar sensitivity, physical tiredness, muscle weakness, changes in glucose levels, and vulnerability to the onset of other comorbidities, which further compromise functionality ${ }^{(2)}$. Also, in the elderly population, the aging process is linked to physiological changes in the musculoskeletal and nervous system, which, together with the complications generated by the disease, cause limitations in the ability of these individuals to perform their daily activities ${ }^{(1,13)}$.

Limitations or illnesses interfere with the independence and autonomy of the elderly person, negatively influencing their emotions, self-image, and safety. Thus, multidimensional assessment becomes an important tool of nurses working in gerontogeriatric/ care to evaluate the health of the elderly person and make decisions about interventions by investigating their individual, family and social conditions of using the functional support networks and cognitive and those related to affectivity ${ }^{(14)}$.

Corroborating this study, a study carried out in the Family Health Units of the state of Ceará identified a decline in the functional capacity of the elderly person with diabetes, in which most had partial dependence $^{(4)}$. The functional evaluation of the elderly person with diabetes should be contextualized and individualized, considering the potential of each one, not only the disability, being initiated early rehabilitation for sequels prevention and the return to activities and community, with consequent inclusion ${ }^{(15)}$.

The correlation between resilience and functional capacity evidenced a positive relationship between both since the increase of one generates influence on the elevation of the other. Thus, functional capacity is an important tool for the development of resilience in the elderly person with diabetes.

The investigation of resilience in people with chronic conditions is becoming more frequent due to the characteristics of the events triggered by them, which generate drastic changes in the daily life of these individuals ${ }^{(5)}$. Therefore, people with severe functional impairment who have limitations that interfere significantly in their life have low levels of resilience due to a greater tendency for exposure to stress and losses in coping with adversity, triggering symptoms of anxiety, depression, anger, low self-esteem and social isolation ${ }^{(16)}$.

Similar research was carried out in China with elderly people with diabetes, in which it was shown that such subjects are predisposed to present a greater fragility in functional capacity. However, as they become more independent, they manifest a positive confrontation with eventual problems that may arise $\mathrm{e}^{(17)}$.

Support network is an important tool in the patient's coping and adaptation to adverse life situations, such as stress and illness, which results in positive behaviors. Commonly, the family is the largest source of social support, as well as neighbors and friends, as well as health professionals who are involved in the process $^{(18)}$.

In this sense, nursing practice must contemplate the real needs of the elderly person with diabetes, essential to form an effective relationship with the individual and their families, in the search for the development of strategies that can favor the construction of resilience and improve the functional capacity ${ }^{(19)}$. Among them, there is a stimulus for social interactions, strengthening of emotional ties, identification of pleasurable activities for the elderly person, orientation for foot care and the use of appropriate footwear, among others ${ }^{(20)}$.

\section{Conclusion}

The results showed that most of the elderly participants were functionally dependent, which shows the influence of the complications of diabetes, but they were resilient in the face of adversity. When correlating resilience with the functional capacity of the 
elderly person, a positive proportional relationship was observed between these variables, highlighting the functional capacity as an important instrument for the development of resilience in the elderly person affected by chronic diseases, in particular diabetes mellitus because the psychomotor activity is commonly compromised in this area of disease.

\section{Collaborations}

Frazão MCLO, Pimenta CJL, Silva CRR and Vicente $\mathrm{MC}$ contributed to the design and project, analysis and interpretation of the data. Costa TF and Costa KNFM contributed to the relevant critical review of the intellectual content and final approval of the version to be published.

\section{References}

1. Araújo EC, Martins KP, Lima RJ, Costa KNFM. Concern with falls in elderly people attended in Integral Attention Center. Rev Eletr Enf. 2016; 18:e1186. doi: http://dx.doi.org/10.5216/ree. v18.39899

2. Downer B, Rote S, Markides KS, Snih AS. The comorbid influence of high depressive symptoms and diabetes on mortality and disability in Mexican Americans aged 75 and above. Gerontol Geriatr Med. 2016; 2:2333721416628674. doi: http://dx.doi.org/10.1177/2333721416628674

3. Komiyama T, Ohi T, Miyoshi $\mathrm{Y}$, Murakami T, Tsuboi A, Tomata Y, Tsuji I, et al. Association between tooth loss, receipt of dental care, and functional disability in an elderly Japanese population: the Tsurugaya project. J Am Geriatr Soc. 2016; 64(12):2496-2502. doi: http://dx.doi. org/10.1111/jgs.14390

4. Muniz EA, Aguiar MFS, Brito MCC, Freitas CASL, Moreira ACA, Araújo CRC. Desempenho nas atividades básicas da vida diária de idosos em atenção domiciliar na Estratégia Saúde da Família. Rev Kairós Gerontol [Internet]. 2016 [citado 2018 jun. 01]; 19(2):133-46. Disponível em: https:// revistas.pucsp.br/index.php/kairos/article/ view/30365/20994
5. Böell JEW, Silva DMGV, Hegadooren KM. Sociodemographic factors and health conditions associated with the resilience of people with chronic diseases: a cross sectional study. Rev Latino-Am Enfermagem. 2016; 24:e2786. doi:http://dx.doi.org/10.1590/15188345.1205 .2786

6. César CC, Mambrini JVM, Ferreira FR, Lima-Costa MF. Capacidade funcional de idosos: análise das questões de mobilidade, atividades básicas e instrumentais da vida diária via Teoria de Resposta ao Item. Cad Saúde Pública. 2015; 31(5):931945.doi:http://dx.doi.org/10.1590/0102311X00093214

7. Pesce RP, Assis SG, Avanci JQ, Santos NC, Malaquias JV, Carvalhaes R. Adaptação transcultural, confiabilidade e validade da escala de resiliência. Cad Saúde Pública. 2005; 21(2):436-48. doi: http://dx.doi.org/10.1590/S0102-311X2005000200010

8. Yang Y, Wen M. Psychological resilience and the onset of activity of daily living disability among older adults in china: a nationwide longitudinal analysis. J Gerontol B Psychol Sci Soc Sci. 2014; 70(3):470-80. doi: http://dx.doi.org/10.1093/ geronb/gbu068

9. Minosso JSM, Amendola F, Alvarenga MRM, Oliveira MAC. Validation of the Barthel Index in elderly patients attended in outpatient clinics, in Brazil. Acta Paul Enferm. 2010; 23(2):218-23. doi: http://dx. doi.org/10.1590/S0103-21002010000200011

10. Lemos CMM, Moraes DW, Pellanda LC. Resilience in patients with ischemic hearth disease. Arq Bras Cardiol. 2016; 106(2):130-5. doi: http://dx.doi. org/10.5935/abc.20160012

11. Persson J, Levin LA, Holmegaard L, Redfors P, Jood $\mathrm{K}$, Jern C, et al. Stroke survivors' long-term QALYweights in relation to their spouses' QALY-weights and informal support: a cross-sectional study. Health Qual Life Outcomes. 2017; 15(150):1-10. doi:http://dx.doi.org/10.1186/s12955-0170724-7

12. Robinson M, Hanna E, Raine G, Robertson S. Extending the comfort zone: building resilience in older people with long-term conditions. J Appl Gerontol. 2017; 1:733464817724042. doi: http:// dx.doi.org/10.1177/0733464817724042 
13. Lima RJ, Pimenta CJL, Bezerra TA, Viana LRC, Ferreira GRS, Costa KNFM. Functional capacity and risk of falls in the elderly. Rev Rene. 2017; 18(5):616-22. doi: http://dx.doi. org/10.15253/2175-6783.2017000500008

14. Leonardo KC, Talmelli LFS, Diniz MA, Fhon JRS, Fabricio-Wehbe SCC, Rodrigues RAP. Assessment of cognitive status and frailty of elder elderly living at home. Cienc Cuid Saude. 2014; 13(1):120-7. doi: http://dx.doi.org/10.4025/cienccuidsaude. v13i1.20033

15. Fontes AP, Fattori A, D'Elboux MJ, Guariento ME. Resiliência psicológica: fator de proteção para idosos no contexto ambulatorial. Rev Bras Geriatr Gerontol. 2015; 18(1):7-17. doi: http://dx.doi. org/10.1590/1809-9823.2015.13201

16. Carvalho IG, Bertolli ES, Paiva L, Rossi LA, Dantas RAS, Pompeo DA. Anxiety, depression, resilience and self-esteem in individuals with cardiovascular diseases. Rev Latino-Am Enfermagem. 2016; 24:e2836. doi: http://dx.doi.org/10.1590/15188345.1405 .2836
17. Chhetri JK, Zheng Z, Xu X, Ma C, Chan P. The prevalence and incidence of frailty in prediabetic and diabetic community-dwelling older population: results from Beijing longitudinal study of aging II (BLSA-II). BMC Getriatr. 2017; 17(47):1-8. doi: http://dx.doi.org/10.1186/ s12877-017-0439-y

18. Holanda CMA, Andrade FLJP, Bezerra MA, Nascimento JPS, Neves RF, Alves SB, et al. Support networks and people with physical disabilities: social inclusion and access to health services. Ciênc SaúdeColetiva.2015;20(1):175-84. doi:http://dx.doi.org/10.1590/1413-81232014201.19012013

19. Pinto BK, Muniz RM, Schwartz E, Budó MLD, Heck RM, Lange C. Identidade do homem resiliente no contexto de adoecer por câncer de próstata: uma perspectiva cultural. Rev Bras Enferm. 2014; 67(6):942-8. doi: http://dx.doi. org/10.1590/0034-7167.2014670612

20. Galvão-Coelho NL, Silva HPA, Sousa MBC. Resposta ao estresse: II. Resiliência e vulnerabilidade. Estud Psicol. 2015; 20(2):72-81. doi: http://dx.doi. org/10.5935/1678-4669.20150009 